\title{
DGGE and multivariate analysis of a yeast community in spontaneous cocoa fermentation process
}

\author{
A.C.R. Ferreira, E.L.S. Marques, J.C.T. Dias and R.P. Rezende \\ Departamento de Ciências Biológicas, Universidade Estadual de Santa Cruz, \\ Salobrinho, Ilhéus, BA, Brasil \\ Corresponding author: R.P. Rezende \\ E-mail: rezende.rachel@gmail.com
}

Genet. Mol. Res. 14 (4): 18465-18470 (2015)

Received August 13, 2015

Accepted October 7, 2015

Published December 23, 2015

DOI http://dx.doi.org/10.4238/2015.December.23.34

ABSTRACT. Cocoa bean is the main raw material used in the production of chocolate. In southern Bahia, Brazil, cocoa farming and processing is an important economic activity. The fermentation of cocoa is the processing stage that yields important chocolate flavor precursors and complex microbial involvement is essential for this process. In this study, PCRdenaturing gradient gel electrophoreses (DGGE) was used to investigate the diversity of yeasts present during the spontaneous fermentation of cocoa in southern Bahia. The DGGE analysis revealed a richness of 8 to 13 distinct bands of varied intensities among the samples; and samples taken at 24,36 , and $48 \mathrm{~h}$ into the fermentation process were found to group with $70 \%$ similarity and showed the greatest diversity of bands. Hierarchical clustering showed that all samples had common operational taxonomic units (OTUs) and the highest number of OTUs was found in the $48 \mathrm{~h}$ sample. Variations in $\mathrm{pH}$ and temperature observed within the fermenting mass over time possibly had direct effects on the composition of the existing microbial community. The findings reported here indicate that a heterogeneous yeast community is involved in the complex cocoa 
fermentation process, which is known to involve a succession of specialized microorganisms.

Key words: Domain D1/D2; 26 s rDNA; DGGE-PCFR; Cocoa fermentation

\section{INTRODUCTION}

The physiological diversity of yeasts favors survival and ubiquity in different environments. The spontaneous cocoa fermentation process starts with yeasts without a domain of one specie showing interesting variations (Thompson et al., 2001). The distribution of yeast in such processes can follow a succession, influenced by conditions such as aeration, $\mathrm{pH}$, and sugar concentration (Lehrian and Patterson, 1983; Schwan, 1995; Schwan and Wheals, 2004). In studies of complex microbial communities such as that involved in cocoa fermentation, Denaturing Gradient Gel Electrophoresis (DGGE) allows a temporal and spatial assessment of the community present to be made (Nielsen et al., 2005; Nielsen et al., 2007, Santos et al., 2011). In the case of yeasts, total DNA from the samples is amplified with primers targeting the D1/D2 domains of the 26S rDNA subunit.

During cocoa fermentation, yeasts are responsible for the breakdown of citric acid in the slurry, which leads to an increase in $\mathrm{pH}$, which in turn allows for bacterial growth. Under low oxygen conditions such bacterial growth results in ethanol production; and at high concentrations of sugars, organic acids (oxalic, phosphoric, succinic, malic acid, and acetic acid) are produced. These organic acids permeabilize and kill the germ of the cocoa beans, leading to the production of volatile organic compounds that contribute to both the chocolate flavor precursors and subsequently the chocolate flavor. Finally, the secretion of pectinase, which reduces the viscosity of the pulp, allows for greater aeration of the fermentation mass (Schwan, 1998; Crafack et al., 2013).

Over the last decade, few studies have been carried out on cocoa fermentation in the Bahia region of Brazil and the aim of this study was thus to assess the molecular complexity of the yeast community in spontaneous cocoa fermentation in this region using DGGE to determine the yeast profile of this complex system.

\section{MATERIAL AND METHODS}

\section{Sampling}

Sampling was carried out at São Jorge farm in the city of Ilhéus, in the southern region of Bahia. Cocoa beans $(200 \mathrm{~g})$ were collected from $800 \mathrm{~kg}$ fermenting boxes at $12 \mathrm{~h}$ intervals until the last day of the cocoa fermenting process. Pulp samples were taken from the central portion of the fermentation boxes ( $40 \mathrm{~cm}$ from the box wall and $60 \mathrm{~cm}$ from the surface) and transferred to sterile plastic bags. The pulp was separated from the beans with a de-pulper (Arno, São Paulo, SP, Brazil), after which a solution containing $0.1 \%$ peptone (Difco, Lawrence, KS, USA), and $0.1 \%$ Tween $^{\circledR} 80$ (Sigma Ultra, St. Louis, MO, USA) was added to the pulp fraction.

\section{Temperature and $\mathrm{pH}$ measurements during cocoa fermentation}

The temperature of the fermentative mass was determined using a $70 \mathrm{~cm}$ thermometer (Gulterm 180, Gulton, São Paulo, SP, Brazil) inserted into the center of the mass. After the separation from the bean, the pulp was subjected to $\mathrm{pH}$ testing using an electrode of a potentiometer (PG 1800 Genaka, São Paulo, SP, Brazil) previously calibrated with standard pH 4.0 and 7.0 buffers. 


\section{Yeast quantification and storage}

One $\mathrm{mL}$ pulped fraction of each sample was serially diluted to dilutions of $1 / 10^{-3}$ to $1 / 10^{-7}$. Diluted yeast samples $(100 \mu \mathrm{L})$ were plated onto Sabouraud agar (Difco) containing chloramphenicol (100 mg/L) and incubated at $25^{\circ} \mathrm{C}$ in BOD (Quimis, São Paulo, SP, Brazil) for $96 \mathrm{~h}$, allowing colony forming units (CFU) to be quantified. The resulting colonies were isolated in pure culture and morphophysiologically characterized. The isolated yeasts were subsequently stored in GYMP (3 g/L yeast extract, $3 \mathrm{~g} / \mathrm{L}$ malt extract, $5 \mathrm{~g} / \mathrm{L}$ bacteriological peptone, $10 \mathrm{~g} / \mathrm{L}$ glucose, $20 \mathrm{~g} / \mathrm{L}$ agar, $20 \%$ [v/ v] glycerol) at $4^{\circ} \mathrm{C}$ under a layer of sterile mineral oil.

\section{Total DNA extraction}

Frozen pulp samples were defrosted at ambient temperature and each sample $(14 \mathrm{~mL})$ was transferred to a $15 \mathrm{~mL}$ tube used for genetic material extraction. Samples were centrifuged (Eppendorf Minispin, Hamburg, Germany) at 3000g in TE buffer (50 mM Tris- $\mathrm{HCl}, 50 \mathrm{mM}$ EDTA, $\mathrm{pH} 8.4)$ and the supernatants were discarded. Pellets were washed 3 times in sodium phosphate buffer (50 mM, pH 7) before being suspended in $1 \mathrm{~mL}$ TESC buffer (100 mM Tris- $\mathrm{HCl}, \mathrm{pH} 8.3$ ). Samples were macerated in liquid nitrogen, after which $10 \mu \mathrm{L}$ dimethyl sulfoxide (DMSO) was added and samples were homogenized by vortex (Phoenix AP56, Araraquara, SP, Brazil). Proteinase K $(12 \mu \mathrm{L}, 20 \mathrm{mg} / \mathrm{mL})$ and sodium dodecyl sulfate (SDS; $12 \mu \mathrm{L}, 25 \%)$ was added to the homogenate and the mixture was incubated for $60 \mathrm{~min}$ at $37^{\circ} \mathrm{C}$ (Eletrolab, São Paulo, SP, Brazil). The mixture was then subjected to three cycles of thermal shock in liquid nitrogen and hot water $\left(80^{\circ} \mathrm{C}\right.$, Logen Scientific water bath, Lagos, Nigeria), after which the samples were centrifuged at $3000 \mathrm{~g}$ for 2 minutes. The resulting supernatants were discarded and a volume of phenol-chloroform-isoamyl alcohol (Sigma-Aldrich, St. Louis, MO, USA) (25:24:1) equal to the supernatant volume was added to each pellet. The sample was centrifuged at $4^{\circ} \mathrm{C}$ and $3000 \mathrm{~g}$ for 10 minutes, after which the resulting supernatant was collected and transferred to $2 \mathrm{~mL}$ tubes. For DNA precipitation, frozen isopropanol and sodium acetate were added to the supernatant and the solution was left to precipitate overnight in freezer at $-20^{\circ} \mathrm{C}$ (Eletrolux, Curitiba, PR, Brazil). The resulting pellet was centrifuged at $4^{\circ} \mathrm{C}, 3000 \mathrm{~g}$ for 10 minutes after which the precipitate was washed with ethanol $70 \%$ (at $-20^{\circ} \mathrm{C}$ ) and centrifuged again. The supernatant was discarded and the precipitate was allowed to dry for 40 minutes before being resuspended in $100 \mu \mathrm{L}$ classic TE buffer $(10 \mathrm{mM}$ Tris- $\mathrm{HCl}, 1$ mM EDTA, pH 7.4). The DNA was purified by gel filtration chromatography using Sephadex G-200 (Amersham Biosciences, Piscataway, NJ, USA) resin.

\section{PCR-DGGE}

A fragment of the D1 region of the 26S rRNA gene was amplified (Eppendorf Mastercycle Nexus Gradient, Hamburg, Germany) using the universal eukaryote primers (IDT, Coral Ville, IA, USA) NL1GC (5'- CGC CCG CCG CGC GCG GCG GGC GGG GCG GGG GCA TAT CAA TAA GCG GAG GAA AAG-3') and LS2 (5'- ATT CCC AAA CAA CTC GAC TC-3') (Cocolin et al., 2000; Nielsen et al., 2005). All PCR reactions were carried out with a reaction mixture of $5 \mathrm{U} / \mu \mathrm{L}$ Taq polymerase (Invitrogen, Grand Island, NY USA), 5X reaction buffer, $10 \mathrm{mM}$ deoxy-nucleotide (IDT, Coral Ville, IA, USA), $25 \mathrm{mM} \mathrm{MgCl} 2,1 \mu \mathrm{L}$ DNA, and sterile Milli-Q water in a final volume of $50 \mu \mathrm{L}$. He PCR cycling conditions were as follows: 5 minutes of denaturation at $95^{\circ} \mathrm{C} ; 35$ cycles of $95^{\circ} \mathrm{C}$ for $60 \mathrm{~s}, 52^{\circ} \mathrm{C}$ for $45 \mathrm{~s}, 72^{\circ} \mathrm{C}$ for $60 \mathrm{~s}$; followed by a final extension step of $72^{\circ} \mathrm{C}$ for 7 minutes. The 
sizes and quantities of the resulting PCR products were determined by subjecting $5 \mu \mathrm{L}$ reaction products to agarose gel electrophoresis (1\% agarose) for 30 minutes at $100 \mathrm{~V}$. The DNA was visualized by staining the gel with ethidium bromide (Sigma-Aldrich). The DGGE analysis of the DNA samples was carried out as described by Muyzer et al. (1993) (Biorad, Hercules, CA, USA). Polyacrylamide gel (6\%) and acrylamide:bis-acrylamide (37.5: 1) were prepared in 1X TAE buffer (0.04 M Tris base, $1 \mathrm{M}$ glacial acetic acid, $50 \mathrm{mM}$ EDTA, $\mathrm{pH}$ 8) using a denaturing gradient of 35$65 \%$ [ $100 \%$ denaturing corresponding to $7 \mathrm{M}$ urea and $40 \%(\mathrm{v} / \mathrm{v})$ formamide]. This gel was run in $1 \mathrm{X}$ TAE buffer at a constant temperature of $60^{\circ} \mathrm{C}$ for 15 minutes at $60 \mathrm{~V}$ initially, and then for a further $4 \mathrm{~h}$ at $200 \mathrm{~V}$. The gel was visualized after it was stained in ethidium bromide solution $(1 \mu \mathrm{g} /$ $\mathrm{mL}$ ) for 30 minutes and photographed in a UV transilluminator.

\section{Multivariate analysis}

Three methods of multivariate analysis were applied: 1, Cluster analysis; 2, Cluster analysis preceded by principal component analysis (PCA); and 3, Venn diagram for a comparison of results. The first methodology of cluster analysis was based on the binary matrix, representing the presence or absence of bands following each treatment. A similarity matrix was obtained by calculating the coefficient of Dice. In the second method, PCA was applied to reduce the dimension of the original variables, while in the third method, Venn diagrams were constructed manually to take into account the intersections of the DGGE bands obtained.

\section{RESULTS AND DISCUSSION}

The role of microorganisms in cocoa fermentation has not been fully elucidated; however, it is clear that some of the chemical changes that occur in the pulp during the fermentation process can be attributed to the microorganism community. The $\mathrm{pH}$ of the fermentative mass was initially 4.0 before rapidly declining $(12 \mathrm{~h}$ ) and then progressively increasing from $48 \mathrm{~h}$ until the end of the fermentative process $(108 \mathrm{~h})$, and which point the $\mathrm{pH}$ was 4.7 (Figure 1A). This same effect was observed in fermentation processes studied by Jespersen et al. (2004). The variation of the temperature in cocoa mass during the process was of $32^{\circ} \mathrm{C}$ during the data gathering in the initial steps, up to $52^{\circ} \mathrm{C}$ (Figure 1A). The temperature of the fermenting cocoa mass was found to rise slowly in the beginning of the process, increasing quickly after the first $48 \mathrm{~h}$, at which point it was found to be at $40^{\circ}-45^{\circ} \mathrm{C}$. With daily rotation of cocoa beans from one box to another to facilitate homogenization and aeration of the beans, temperatures can reach even higher levels of up to $50^{\circ} \mathrm{C}$ after $72 \mathrm{~h}$ of the beginning of the fermentation process (Lehrian and Patterson, 1983; Schwan, 1995; Ardhana and Fleet, 2003). Yeast counts are shown in Figure 1B. After $12 \mathrm{~h}$ of fermentation the yeast count was found to peak $(4.5 \mathrm{x}$ $10^{7} / \mathrm{mL}$ ), after which the count declined throughout the remainder of the process; however, yeasts were still present in low quantities at the end of the process.

DNA was extracted from all cocoa pulp samples from the selected time points in the fermentation process. After purification, the DNA samples were subjected to PCR, which in each case yielded a product of $250 \mathrm{bp}$. The 250-bp products were used in the subsequent DGGE analysis, generating band profiles which revealed a richness of 8 to 13 distinct bands of varied intensities, when developed in polyacrylamide gel at $6 \%$ in a gradient $(35-65 \%)$ of denaturing agents (Figure 2A). The samples collected during the initial period of fermentation $(24,36,48$ h) grouped with $70 \%$ similarity and showed the greatest diversity of bands (Figure 2B), while samples from the final and intermediary periods $(60,72,84 \mathrm{~h})$ did not group together (Figure 2B). 
The hierarchical clusters generated from the banding pattern obtained from PCR-DGGE analysis showed that all samples had a common operational taxonomic unit (OTU; Figure 2C) and that the samples taken at the beginning and the end of the fermentation process $(0,12,96,108$, and 120 h) had only a single OTU forming a clade with $100 \%$ similarity (Figure 2D). Principal Component Analyses (PCA) confirmed the clustering of the samples from the $0,12,96,108$, and $120 \mathrm{~h}$ time points (Figure 2E). In a previous study, Nielsen et al. (2005) reported 16 bands in the DGGE profile of samples collected from cocoa fermentation trays and heaps in Ghana.
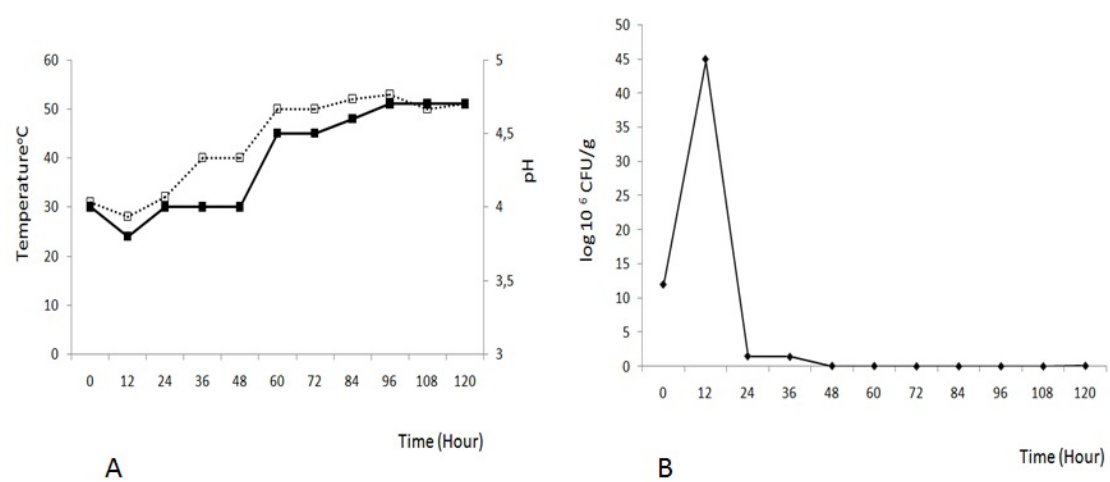

Figure 1. Time course analysis of $\mathrm{pH}$, temperature, and yeast count during cocoa fermentation. $\mathbf{A}$. $\mathrm{pH}$ (open squares) and temperature (filled squares) meaurements taken at $12 \mathrm{~h}$ intervals during $120 \mathrm{~h}$ of fermentation. B. Yeast count (CFU: colony forming unit) measured at $12 \mathrm{~h}$ intervals until the last day of cocoa fermentation.

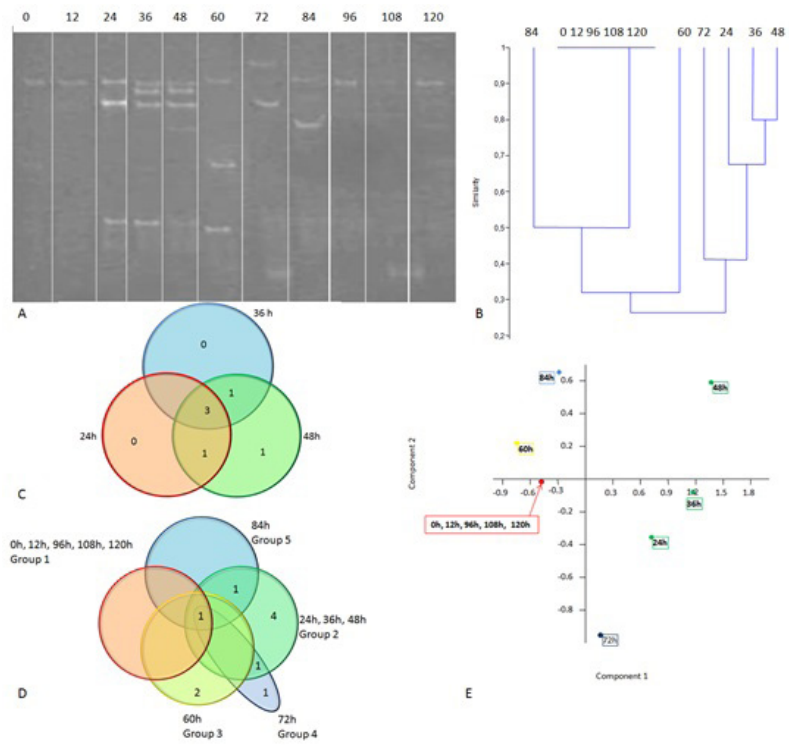

Figure 2. DGGE profile of yeast DNA amplified with NL1GC and LS2 primers targeting the D1 domain of the 26S rRNA gene (A); dendrogram representation of the similarities within the yeast community present in samples analyzed at 12 $\mathrm{h}$ intervals (B); Venn diagram showing common OTUs between different time points (C and $\mathbf{D})$; principal component analysis (PCA) based on the DGGE profiles of yeasts (E). All data in the figure demonstrate more clustering of the microbial communities at the $0,12,96,108$, and $120 \mathrm{~h}$ time points than that at the other time points. 


\section{CONCLUSIONS}

The findings reported here demonstrate the versatility of DGGE as a means of showing the clustering of yeasts as well as the importance of culture-dependent techniques to harness the biotechnological potential of yeasts. Identification of the yeast species found in this study would require sequence analysis.

\section{ACKNOWLEDGMENTS}

Research supported Conselho Nacional de Pesquisa e desenvolvimento (CNPq) process \#558272/2009-6. Scholarship grants for Eric de Lima Silva Marques were provided by Fundação de Amparo a pesquisa do Estado da Bahia (FAPESB). Our thanks to the cocoa producers José Maria Reis (farm São Jorge) for supporting this study.

\section{REFERENCES}

Ardhana MM and Fleet HG (2003). The microbial ecology of cocoa bean fermentations in Indonesia. Int. J. Food Microbiol. 86: 87-99.

Cocolin L, Bisson LF and Mills DA (2000). Direct profiling of the yeast dynamics in wine fermentations. FEMS Microbiol. Lett. 189: $81-87$

Crafack M, Mikkelsen MB, Saerens S, Knudsen M, et al. (2013). Influencing cocoa flavour using Pichia kluyveri and Kluyveromyces marxianus in a de- fined mixed starter culture for cocoa fermentation Int. J. Food Microbiol. 167: $103-116$.

Jespersen L, Nielsen DS, Hønholt S and Jakobsen M (2004). Occurrence and diversity of yeasts involved in fermentation of West African cocoa beans. FEMS Yeast Res. 5: 441-453.

Lehrian DW and Patterson GR (1983). Cocoa Fermentation. Biotechnology 5:12.

Muyzer G, De Waal EC and Uitterlinder AG (1993). Profiling of complex microbial populations by denaturing gradient gel electrophoresis analysis of polimerase chain reactionamplified genes coding for 16S rRNA. Appl. Environ. Microbiol. 59: 695-700.

Nielsen DS, Hønholt S, Tano-Debrah K and Jespersen L (2005). Yeast populations associated with Ghanaian cocoa fermentations analyzed using denaturing gradient gel electrophoresis (DGGE). Yeast 22: 271-284.

Nielsen DS, Teniola OD, Ban-Koffi L, Owusu M, et al. (2007). The microbiology of Ghanaian cocoa fermentations analyzed using culture-dependent and culture-independent methods. Int. J. Food Microbiol. 114: 168-186.

Santos TF, Santana LK, Santos AC, Silva GS, et al. (2011). Lactic acid bacteria dynamics during spontaneous fermentation of cocoa beans verified by culture-independent denaturing gradient gel electrophoresis. Genet. Mol. Res. 10: $2702-2709$.

Schwan RF, Rose AH and Board RG (1995). Microbial fermentation of cocoa beans, with emphasis on enzymatic degradation of the pulp. J. Appl. Bacteriol. Symp. Suppl. 79: 96-107.

Schwan RF and Wheals AE (2004). The microbiology of cocoa fermentation and its role in chocolate quality. Crit. Rev. Food Sci. Nutr. 44: 205-222.

Thompson SS, Miller KB and Lopez AS (2001). Cocoa and coffee. In: Food Microbiology- Fundamentals and frontiers (Doyle MJ, Beuchat LR and Montville TJ, eds.). ASM Press, Washington, D.C., 721-733. 